\title{
A vida subterrânea e o tempo: uma leitura sobre a implicação entre física e vida em Dostoiévski
}

\author{
Lucas Bizarria Freitas ${ }^{1}$
}

\begin{abstract}
Resumo: A obra de Dostoiévski é perpassada pela recorrente figura do homem subterrâneo. O presente artigo propõe uma análise dessa figura no interior da narrativa Uma Criatura Dócil, tendo em vista colocar em evidência o trabalho conceitual desempenhado pelo autor russo a partir dessas personagens sombrias. Em grande medida, Dostoiévski conduz sua escrita tomado por acontecimentos pungentes que tomam seu tempo cotidiano. Sua sensibilidade a eventos mundanos a atravessar a vida em São Petersburgo permite ao autor russo uma problematização de conceitos insuspeitos, como o tempo e a vida cotidiana. Nessa medida, nossa análise aproxima conceitos próprios da física - do estudo científico dos acontecimentos naturais - e da literatura, de modo a tomar um intenso exemplo de uso literário de conceitos científicos. Tal exemplopode interligar, claramente, a vida e os conceitos físicos. Sugerimos, enfim, que uma aproximação entre literatura e ciências pode emergir a partir de um trabalho conceitual focado no nexo entre o autor - no contexto da produção de sua obra, na vida cotidiana - e a sua materialidade imediata - a física, manifesta no transcorrer temporal. A ligação literatura-ciência se desdobra no interior desse campo vital.
\end{abstract}

Palavras-chave: tempo; cotidiano; homem subterrâneo; física; vida.

\begin{abstract}
Dostoiévski's work is populated by the recurrent figure of the subterranean man. Our paper proposes an analysis around this character within A docile creature, therewith to show up the conceptual work done by the Russian author through those shady men. To a large extent, Dostoiévski conducts his writing through pungent happenings that imprison his daily time. The author's sensibility to mundane events permeating life in Saint Petersburg brings up the questioning of unsuspected concepts, such as time and daily life. Accordingly, our analysis approaches concepts from Physics - the scientific study of natural phenomena - and literature,
\end{abstract}

\footnotetext{
${ }^{1}$ Licenciado em Física pelo Instituto de Física da Universidade de São Paulo (IFUSP) e Mestre em Educação pela Faculdade de Educação da Universidade de São Paulo. Email: lukasbizarria@ gmail.com Publicações mais relevantes: FREITAS, L. B. A comédia como potência de pensamento estudo de um caso. Alegrar (Campinas), v. 3, p. 1-5, 2015. FREITAS, L. B. O corpo como plataforma de (re)configuração do Conhecimento em Ciências. In: XVI Encontro ANPOF, 2015, Campos do Jordão. Coleção XVI Encontro ANPOF - Filosofia da Ciência e da Natureza. São Paulo: ANPOF, 2014. p. 484-501. FREITAS, L. B. A (re)configuração da relação homemmundo como eixo de problematização dos pressupostos pedagógicos modernos. In: VII Colóquio Internacional de Filosofia da Educação, 2014, Rio de Janeiro. O que pode a escola hoje em nossa América?, 2014. FREITAS, L. B.; BENEDYCT, B. I. . Experiências limites ao campo da educação: textos marginais como disparadores do pensamento. In: I Jornada Internacional de Filosofia da Educação, 2014, São Paulo. I Jornada Internacional de Filosofia da Educação:filosofia, educação, formação. São Paulo: Faculdade de Educação da Universidade de São Paulo, 2014. p. 259-268.
} 
so that we can take an intense example of a literary appropriation of scientific concepts. Such example can clearly link life and physical concepts. We suggest, at last, that an approximation between literature and sciences can emerge from a conceptual effort focused in the connection between author - in the context of his work, in his daily life - and his immediate materiality Physics, manifested as the temporal flux. The connection literature-science unfolds itself within life.

Key-words: time; routine; underground man; physics; life.

A obra de Dostoiévski pode ser concebida, em alguma medida, como uma exploração literária de paradoxos. A força desse trabalho sobre o absurdo estaria na tensão capaz de trazer às claras as condições mesquinhas e mínimas de conceitos como o tempo e a própria vida. $\mathrm{O}$ autor russo sugere, assim, uma intimidade entre o cotidiano, a existência imediata e alguns conceitos filosóficos, tal como o tempo e o pensamento. Nesse sentido, Dostoiévski foi capaz de concatenar, através da literatura, a vida das personagens com o pensamento e o trabalho conceitual a partir da exploração de uma figura recorrente em suas obras: o homem subterrâneo. Não se trataria de um traço próprio da obra Memórias do Subsolo (DOSTOIÉVSKI, 2009a). Em diversas outras produções de Dostoiévski emergem essas figuras pequenas e sombrias. Para situar alguns deles, podemos citar Goliádkin, o protagonista de O Duplo (DOSTOIÉVSKI, 2011); o homem inominado de Memórias do Subsolo (DOSTOIÉVSKI, 2009a); Smerdiákov, em Os Irmãos Karamázov(DOSTOIÉVSKI, 2012). Trata-se de sombras, vidas situadas nas margens de uma sociedade desigual e perpassada, ao mesmo tempo, pelo otimismo da modernidade. Tais existências mínimas, marcadas por uma miséria do próprio pensamento, trazem à tona os limites de conceitos característicos da modernidade.

No presente trabalho, nos debruçamos especificamente sobre o tempo a partir de uma precisa leitura da obra Uma Criatura Dócil (DOSTOIÉVSKI, 2009b). Essa curta narrativa, juntamente com a produção da mesma, custou a Dostoiévski um preço. O autor russo liga o desaguar do tempo, conceito trabalhado pela física, à existência do patético protagonista do conto. Por um viés literário, a pequena obra nos convoca a situar o tempo como um problema vital. Dostoiévski une, enfim, o fenômeno da vida cotidiana ao rol dos acontecimentos naturais, sem poupar o leitor das consequências trágicas decorrentes dessa concepção. Tendo em vista essa configuração geral da narrativa, discutamos em pormenor os desdobramentos da obra. 
O conto descreve a tentativa desesperada de um decadente marido em "concentrar o pensamento num ponto" e explicar a cena diante de si: o corpo morto de sua esposa. Toda a narrativa segue em primeira pessoa - um ir e vir nauseante em busca de uma linha causal satisfatória diante da tragédia. A jovem havia se atirado do parapeito alto de uma janela, abraçada a uma imagem sacra. A presença desse detalhe um símbolo sagrado cristão nas mãos de uma suicida - se torna a condição de emergência para a própria narrativa e enlaça, na escrita da tragédia, a vida do próprio autor russo.

Assim, tomemos a ocasião que desencadeou a escrita desse texto na vida do autor. A produção ocorreu após a leitura do jornal Golos (A voz) de uma pequena tragédia. Uma jovem costureira moscovita tentou a sorte em São Petersburgo. Na cidade grande, caiu em miséria e, tomada de desespero, jogou-se do alto de um prédio abraçada a uma imagem da Virgem Maria. Para produzir essa pequena obra, o autor russo cancelou toda a edição regular da revista a qual ele coornedava e publicou umnúmero especial. Nesse volume da revista, constava apenas o conto trágico. Em cartas explicando a pausa total na produção regular em seu empreendimento para a escrita do conto, Dostoiévski (2009b, p. 91) comenta:

Durante muito tempo não conseguimos deixar de pensar em certas coisas, por mais simples que pareçam, elas como nos perseguem, e até parece então que temos culpa dessas coisas. Essa alma doce e humilde que destruiu a si mesma forçosamente tortura o pensamento.

Fica evidente, na própria produção desse conto, um intenso atravessamento de um acontecimento fugaz, que seria condenado ao esquecimento, caso não fosse transformado em uma obra literária. Dostoiévski desviou a produção de um mês em sua revista e o dedicou a essetrabalho. A aniquilação dessa existência, em meio à miserável cidade de Petersburgo, dragou o tempo do autor. Nesse momento de grande sensibilidade, Dostoiévski comporia, diante do sacrifício precoce de uma jovem no confronto com a miséria citadina, um conto no qual essa implicação entre tempo e existência colapsaria de modo intensivo. Portanto, não se trataria de uma obra sobre o tempo, na qual as vidas das personagens, suas discussões e desdobramentos trariam algo a se pensar a respeito do transcorrer temporal. O próprio contexto de produção ao qual Dostoiévski esteve submetido foi uma resposta a uma urgência insuportável, a qual 
demandou a publicação para o alívio dessa tensão sobre o pensamento. Nessa medida, a escrita permeada de ires e vires torturados constituiria, na materialidade das palavras lidas, esse transcorrer iminente e nauseante do tempo. Assim, a afirmação desse devir selvagem emerge da experiência da leitura, desse ato de pensamento sem intermediação de uma suposta interpretação, mas na presença implacável da vida como um evento fortuito no desaguar do tempo. No limite, a criação desse conto constituiu um atravessamento intensivo do transcorrer temporal, característica essa partilhada com o traço desesperado e imediato que permeia toda o pensamento do protagonista. Estamos diante do compartilhamento de uma experiência - de um tratado sobre a íntima implicação entre física e vida, no ato da escrita e da leitura, em toda a extensão dessa curta narrativa.

Dessa forma, há um insight a permear o conto, o qual expõe uma faceta selvagem do tempo. A revelação instantânea dessa crua realidade temporal seria desencadeada, de modo muito similar ao aprisionamento do pensamento que o autor russo experimentou, pelo confronto com a morte. A narrativa seria como a tentativa desesperada do protagonista inominado de compor uma estrutura causal satisfatória. Ele percorre os primeiros encontros com a esposa, em um passado relativamente distante, e retorna sempre aos momentos mais próximos, aos minutos que acabaram de escoar. Esse confronto brutal, concomitante com uma obscuridade incessante a qual impede a descoberta dessa suposta causa da morte, traria à tona o pequeno intervalo de tempo a separar o protagonista do suicídio. Uma questão casual de alguns minutos talvez fosse suficiente para desdobrar essa tragédia em outro cenário. A torturante possibilidade de, com alguns minutos de antecedência, impedir o trágico sucedido, corroi o protagonista. No limite, a tentativa de ordenar, de criar uma sucessão linear de acontecimentos capaz de explicar os fatos, termina por constituir um insuportável quadro: um lance de sorte, combinado com um relance de tempo momentâneo, custou a vida de sua esposa. No limite, a realidade com a qual o protagonista solapa seria a fragilidade da vida contida nos desenlaces de uma temporalidade cotidiana. Com o falecimento da jovem, essa linha de pensamento emergiria com tamanha força que o caráter visceral de nossa existência contida no tempo transtornaria essa tentativa de compor um quadro causal. Afinal, ainda que uma sucessão satisfatória de eventos emergisse dessa tentativa de concentração do pensamento, a realidade da morte da esposa não mudaria. Esse movimento circular apenas reafirmaria o caráter implacável do deseguar do tempo. Um novo paradoxo é explorado por Dostoiévski: a empreitada para a constituição de uma 
explicação racional para o sucedido apenas reafirma uma insensível materialidade - a vida estaria diluída em fortuitos desdobramentos em um devir selvagem, o qual eventualmente emergiria na banalidade de nossas vidas cotidianas. A situação na qual o protagonista se encontra teria, nesse confronto com o termo da vida, a condição de tensão máxima do pensamento. Pensar, seguindo a sugestão deixada por esse pequeno conto, seria ter claros os fundamentos arenosos sobre os quais se apoiam nossas fortuitas existências. A partir desse contexto, emergiria a constatação mais contundente da narrativa:

Dizem que o Sol dá vida ao universo. O Sol está nascendo, olhem para ele, por acaso não é um cadáver? Tudo está morto, e há cadáveres por toda parte. Os homens estão sozinhos, rodeados pelo silêncio - isso é a terra! [...] O pêndulo bate de um modo insensível, nauseante.(DOSTOIÉVSKI, 2009b, p. 88, grifos nossos)

Por meio dessa constatação, um laço entre a existência e os fenômenos naturais se configuraria. Não apenas nossas vidas estariam em jogo nesse devir incessante, mas também o Sol e sua grandeza. No limite, diante do transcorrer temporal, nem mesmo o Sol teria condições de escapar a essa oscilação incessante de um pêndulo. Por paradoxal que pareça, um pequeno objeto em um movimento regular de ida e volta traria à tona essa diluição de todas as existências no devir.

A constatação do caráter passageiro em todos os níveis - desde a vida cotidiana até a existência cósmica da estrela - se torna uma consequência da experiência de leitura, antes de constituir uma decorrência lógica de argumentos dispostos ao longo da narrativa. Nessa medida, a ligação entre a física, manifesta a partir do devir selvagem a engolfar todas as existências, sejam grandes ou pequenas, e a vida cotidiana do protagonista e de sua falecida esposa se manifesta a partir do acontecimento literário, da experiência tanto da leitura quanto da escrita. Portanto, a literatura de Dostoiévski permite uma integração entre campos classicamente classificados como díspares, como a física, a vida e a narrativa.

Tendo em vista essas constatações, podemos apontar na obra do autor russo uma grande fertilidade para a interlocução entre disciplinas tomadas como estanques ou muito disparatadas. Trata-se de um raro cruzamento de diferentes temas - física, narrativa, cotidiano - no qual todos esses elementos permeiam a obra de modo a lançar questões instigantes para nossas vidas. Apresentamos, enfim, um questionamento para 
os físicos e os pesquisadores das ciências naturais: em que medida podemos assumir a empreitada investigativa da natureza, quando nossas vidas estariam implicadas nesse devir, nessa natureza em transformação? Como podemos transformar em objeto essa nua realidade com a qual estamos tão intimamente interligados? Eis algumas interrogações derivadas da leitura de um autor de grande sensibilidade do campo literário aos pesquisadores das ciências naturais.

\section{Referências bibliográficas}

DOSTOIÉVSKI, F. Memórias do subsolo. 6ª edição. São Paulo: Editora 34, 2009a, 147 p. . O duplo. $1^{\text {a }}$ edição. São Paulo: Editora 34, 2011, 253 p. . Os Irmãos Karamázov. $3^{\text {a }}$ edição. São Paulo: Editora 34, 2012, 999p. . Uma criatura dócil. $2^{\mathrm{a}}$ edição. São Paulo: Cosac Naify, 2009b, 97 p. 